\title{
Além do SARS-CoV-2, as implicações da Síndrome Pós COVID-19: o que estamos produzindo?
}

In addition to SARS-CoV-2, the implications of Post COVID-19 Syndrome: what are we producing?

Además del SARS-CoV-2, las implicaciones del Síndrome Post COVID-19: ¿qué estamos produciendo?

\author{
Audrey Moura Mota Gerônimo \\ ORCID: https://orcid.org/0000-0003-0193-0253 \\ Universidade Federal de Alagoas, Brasil \\ E-mail: audreymmoura@gmail.com \\ Isabel Comassetto \\ ORCID: https://orcid.org/0000-0002-2389-9384 \\ Universidade Federal de Alagoas, Brasil \\ E-mail: isabelcomassetto@gmail.com \\ Cinthia Rafaela Amaro Gonçalves Andrade \\ ORCID: https://orcid.org/0000-0003-3805-8825 \\ Universidade Federal de Alagoas, Brasil \\ E-mail: cinthiagoncalves05@gmail.com \\ Raíssa Rafaella Santos Moreno da Silva \\ ORCID: https://orcid.org/0000-0002-7265-9352 \\ Universidade Federal de Alagoas, Brasil \\ E-mail: raissarafaella13@gmail.com
}

\begin{abstract}
Resumo
Objetivo: Analisar a produção científica em periódicos nacionais e internacionais referente à síndrome Pós COVID-19, no período de 2019-2021. Questão norteadora: "Quais as consequências decorrentes da infecção pelo SARS-CoV-2 para o organismo humano?" Métodos: Trata-se de um estado da arte a respeito da síndrome pós Covid, cuja busca foi realizada na base de dados LILACS e Medline com os termos "COVID-19", "Doença por Coronavírus-19", "Infecções por SARS-CoV-2", "Infecções por Coronavírus", "Pós COVID-19”, no recorte temporal de 2019-2021, tendo como critério de inclusão: artigo disponível na íntegra e está publicado em língua portuguesa, Inglesa e Espanhola. Selecionou-se 16 artigos. Resultados: Enfrentar o SARS-CoV-2 vai além de enfrentar um vírus desconhecido, que resulta no desenvolvimento de uma doença igualmente desconhecida, mas que está nos levando ao confronto com nossas próprias limitações enquanto seres humanos, imperfeitos e limitados. Assim, surgem as sequelas físicas em pessoas que superaram a COVID-19. Conclusão: Nem sempre é a pessoa assistida em estado grave que apresenta comprometimentos significativos no pós adoecimento, permanecendo após a recuperação da infecção com algum tipo persistente de sequela. A síndrome pós COVID-19 representa um quadro clínico que é resultante da repercussão do agravo no organismo e que é composto por um conjunto de sintomas inespecíficos. Em sendo um algo recente, ainda não se sabe muito a seu respeito, mas o que fica claro é que não acomete apenas pessoas que desenvolveram a forma grave da COVID-19 e que chegaram a ser internadas em UTI por longo período.
\end{abstract}

Palavras-chave: SARS-CoV-2; COVID-19; Expectativa de vida livre de incapacidades.

\begin{abstract}
Objective: To analyze the scientific production in national and international journals regarding the Post COVID-19 syndrome, in the period 2019-2021. Guiding question: "What are the consequences of SARS-CoV-2 infection for the human body?" Methods: This is a state of the art regarding post-Covid syndrome, which was searched in the LILACS and Medline database with the terms "COVID-19", "Coronavirus-19 disease", "SARS-CoV-2 infections", "Coronavirus Infections", "Post COVID-19", in the 2019-2021 timeframe, with the inclusion criteria: article available in full and is published in Portuguese, English and Spanish. 16 articles were selected. Outcomes: Tackling SARS-CoV-2 goes beyond tackling an unknown virus, which results in the development of an equally unknown disease, but which is leading us to confront our own limitations as human beings, imperfect and limited. Thus, physical sequelae appear in people who have overcome COVID-19. Conclusion: It is not always the person assisted in serious condition who presents significant impairments in the post-illness, remaining after recovery from the infection with some persistent type of sequel. PostCOVID-19 syndrome represents a clinical picture that results from the repercussion of the disease in the body and is
\end{abstract}


composed of a set of nonspecific symptoms. As it is something recent, not much is known about it, but what is clear is that it does not only affect people who developed the severe form of COVID-19 and who were hospitalized in the ICU for a long period.

Keywords: SARS-CoV-2; COVID-19; Disability free life expectancy.

\begin{abstract}
Resumen
Objetivo: Analizar la producción científica en revistas nacionales e internacionales sobre el síndrome Post COVID-19, en el período 2019-2021. Pregunta orientadora: "¿Cuáles son las consecuencias de la infección por SARS-CoV-2 para el cuerpo humano?" Métodos: Este es un estado del arte con respecto al síndrome post-COVID-19, que se buscó en la base de datos de LILACS y Medline con los términos "COVID-19", "Enfermedad por coronavirus-19", "Infecciones por SARS-CoV-2", " Infecciones por Coronavirus "," Post COVID-19 ", en el período 2019-2021, con los criterios de inclusión: artículo disponible en su totalidad y publicado en portugués, inglés y español. Se seleccionaron 16 artículos. Resultados: Abordar el SARS-CoV-2 va más allá de combatir un virus desconocido, que da como resultado el desarrollo de una enfermedad igualmente desconocida, pero que nos enfrenta a nuestras propias limitaciones como seres humanos, imperfectas y limitadas. Así, aparecen secuelas físicas en personas que han superado el COVID-19. Conclusión: No siempre es la persona asistida en estado grave quien presenta deficiencias significativas en la pos-enfermedad, quedando luego de la recuperación de la infección con algún tipo de secuela persistente. El síndrome post-COVID-19 representa una condición clínica que resulta de la repercusión de la enfermedad en el organismo y se compone de un conjunto de síntomas inespecíficos. Como es algo reciente, no se sabe mucho al respecto, pero lo que está claro es que no solo afecta a las personas que desarrollaron la forma severa del COVID-19 y que estuvieron hospitalizadas en la UCI por un largo período.
\end{abstract}

Palabras clave: SARS-CoV-2; COVID-19; Esperanza de vida sin discapacidad.

\title{
1. Introdução
}

A respeito da Covid-19, pontua-se que esta é uma doença resultante do vírus Trata-se de um estudo da arte, que objetivou analisar produção científica em periódicos nacionais e internacionais referente à Síndrome Pós COVID-19, no período de 20192021, para aproximação e aprofundamento teórico da produção do conhecimento a respeito da temática e desenvolvimento da dissertação de mestrado intitulada: “A percepção do vivido pelas pessoas com sequelas decorrentes da COVID-19”, aprovada pelo CEP/UFAL, CAAE de $n^{\circ}$. 41216620.6.0000.5013, com parecer $n^{\circ}$. 4.506.421 de 21/01/2021. O interesse em estudar esta questão surgiu a partir do contexto atual de enfrentamento da pandemia pelo novo Coronavírus e decorrente das inúmeras pessoas que vivenciaram o adoecimento pela COVID-19 e consequentemente evoluíram com sequelas mesmo após a cura da doença.SARS-CoV-2. A COVID-19 é a denominação atual do novo coronavírus surgido em Wuhan (China), em novembro de 2019. Por ser um vírus que apresenta como características relevantes acelerada disseminação, severidade e dificuldade de contenção resultou na declaração do estado pandêmico pela Organização Mundial de Saúde (OMS) três meses após o registro dos primeiros casos. Essa situação exigiu dos diversos países de todo o mundo direcionamento de medidas objetivando a contenção do surto e redução da letalidade (Brasil, 2020).

O Ministério da Saúde no Brasil já em janeiro de 2020, antes mesmo dessa declaração, ativou o Centro de Operações de Emergências em Saúde Pública para o SARS-CoV-2. Convergindo ao previsto no Plano Nacional de Resposta às Emergências em Saúde Pública, restou o desafio de promover a consolidação das informações oficiais e novas evidências técnico-científicas divulgadas para se estruturar os protocolos nacionais de combate à COVID-19. Como etapas essenciais, foram estruturadas medidas de notificação, registro, investigação, manejo e adoção de medidas preventivas para direcionar a conduta dos profissionais da saúde e órgãos governamentais envolvidos no controle dos casos e óbitos em território brasileiro. Ademais, foi construído um consenso de especialistas nacionais e internacionais que resultou na definição do Manejo Clínico da COVID-19 (Brasil, 2020).

Frente a esse cenário, conhecer a respeito da COVID-19, como se dá sua evolução e quais as consequências que provocam no organismo humano se apresenta como prioritário. Inquestionável é a imensa gama de inseguranças e obscuridades em torno do vírus e do agravo, o que exige esforços de todos os segmentos para ir suprindo as lacunas existentes. 
Diante do exposto o objeto proposto para este estudo é "como se dá a infecção pelo SARS-CoV-2 e quais as consequências resultantes da COVID-19 para o organismo humano". Considerando os desafios enfrentados decorrentes desta pandemia, optou-se por este objeto de estudo devido à necessidade da realização de pesquisas que venham construir o conhecimento referente às sequelas decorrentes da COVID-19, a fim de dar subsídios para a assistência às pessoas que tiveram suas vidas alteradas após a infecção pelo SARS-CoV-2. Deste modo, a proposta deste estudo apresenta como questão norteadora: "Quais as consequências decorrentes da infecção pelo SARS-CoV-2 para o organismo humano?".

O presente estudo se justifica pela magnitude que a pandemia da COVID-19 alcançou, exigindo aprender a respeito do vírus e de como compromete o organismo humano, a fim de contribuir na estruturação de estratégias que possibilitem o concreto e eficiente enfrentamento para viabilizar que se supere o cenário atual. Ademais, a importância desse estudo se encontra embasada nos diversos benefícios que se propõe a trazer, no que diz respeito à atenuação dos danos decorrentes do SARS-CoV2, da pandemia e dos estressores a ela associada.

Dessa forma, este estudo pretende construir meios para que a assistência a esse grupo de indivíduos se dê de acordo com suas demandas e necessidades, visto se tratar de um agravo como já apontado desconhecido somado às particularidades do cenário que se está vivendo.

\section{Metodologia}

Trata-se de um estado da arte a respeito da síndrome pós COVID-19, entendendo que este vislumbra um mapeamento da produção do conhecimento a respeito do objeto pelo qual se deseja aproximar/aprofundar, a fim de consolidar e discutir temáticas específicas à luz das evidências científicas. O Estado da Arte, é comumente definido como de caráter bibliográfico, elas parecem trazer em comum o desafio de "mapear e de discutir uma certa produção acadêmica em diferentes campos do conhecimento, tentando responder que aspectos e dimensões vêm sendo destacados e privilegiados em diferentes épocas e lugares, de que formas e em que condições têm sido produzidas". É possível compreender que como metodologia possui caráter descritivo da produção acadêmica e científica sobre o tema que busca investigar, à luz de categorias e facetas que se caracterizam enquanto tais em cada trabalho e no conjunto deles, sob os quais o fenômeno passa a ser analisado (Ferreira, 2002). Desta forma, apropriado para realização deste estudo.

Para produção das informações, foi realizada uma busca foi na base de dados Literatura Latino-Americana e do Caribe em Ciências da Saúde (LILACS) e Medical Literature Analysis and Retrieval Sistem on-line (Medline) com os termos "COVID19", "Doença por Coronavírus-19", "Infecções por SARS-CoV-2", "Infecções por Coronavírus", "Pós COVID-19”, no recorte temporal de 2019-2021. Foi utilizado como critério de inclusão: artigo disponível na íntegra, publicado em língua portuguesa, inglesa ou espanhola, em congruência com a temática do estudo.

Para análise dos artigos encontrados, a princípio foi realizada uma leitura flutuante dos títulos e resumos para identificação das publicações de relevância para o objeto do estudo, e depois de selecionados, realizada a leitura na íntegra com fichamento das diferentes abordagens que discorrem sobre definições relacionadas com a temática, as sequelas decorrentes da infecção pelo SARS-CoV-2, suas implicações, quais os impactos socioeconômicos, além das ideologias e da necessária organização dos serviços de Atenção à Saúde em torno do que se tem produzido a respeito da Síndrome Pós COVID-19. Desta forma, selecionou-se 16 publicações sumarizadas no Quadro 1 e que serão apresentados nos resultados e discussão. 
Quadro 1. Sumarização dos artigos selecionados, descrevendo a autoria, título, objetivo e metodologia de cada estudo.

\begin{tabular}{|c|c|c|c|c|}
\hline & AUTORES & TÍTULO & OBJETIVO & METODOLOGIA \\
\hline 1 & $\begin{array}{l}\text { Allegrante, J. P.; } \\
\text { Auld, M. E. \& } \\
\text { Natarajan, S. (2020). }\end{array}$ & $\begin{array}{l}\text { Preventing COVID-19 and its } \\
\text { Sequela: "There is no Magic } \\
\text { Bullet... It's Just Behaviors". } \\
\text { American journal of } \\
\text { preventive medicine, } 59(2), \\
288-92 .\end{array}$ & $\begin{array}{l}\text { Analisar o desafio de prevenir a propagação } \\
\text { do vírus SARS-CoV-2 e a importância central } \\
\text { da mudança de comportamento em toda a } \\
\text { população como única estratégia preventiva } \\
\text { baseada em evidências atualmente disponível } \\
\text { para a COVID-19 e suas sequelas decorrentes } \\
\text { da infecção. }\end{array}$ & $\begin{array}{l}\text { Metodologia } \\
\text { qualitativa, descritiva }\end{array}$ \\
\hline 2 & $\begin{array}{l}\text { Brasil, República } \\
\text { Federativa do. (2021). }\end{array}$ & Painel Coronavírus. 2021. & $\begin{array}{l}\text { Apresentar o cenário brasileiro expressos em } \\
\text { dados epidemiológicos da pandemia de } \\
\text { COVID-19. }\end{array}$ & $\begin{array}{l}\text { Informe institucional } \\
\text { do Ministério da } \\
\text { Saúde }\end{array}$ \\
\hline 3 & 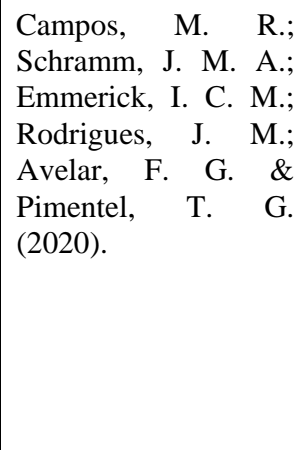 & $\begin{array}{l}\text { Carga de doença da COVID- } \\
19 \text { e de suas complicações } \\
\text { agudas e crônicas: reflexões } \\
\text { sobre a mensuração (DALY) } \\
\text { e perspectivas no Sistema } \\
\text { Único de Saúde. Cadernos de } \\
\text { Saúde Pública, 36(11). }\end{array}$ & $\begin{array}{l}\text { Discutir a relevância e as dificuldades de } \\
\text { estudar a carga da COVID-19 e de suas } \\
\text { complicações, no contexto brasileiro, } \\
\text { ressaltando a importância de caracterizar a } \\
\text { história natural da doença e estimar } \\
\text { indicadores como o YLD, que considerem a } \\
\text { alta carga de morbidade no planejamento de } \\
\text { estratégias para lidar com as consequências da } \\
\text { COVID-19 pós-pandemia. Discute-se também } \\
\text { os desafios futuros para o enfrentamento da } \\
\text { doença no SUS e reflexões sobre o cálculo do } \\
\text { DALY. }\end{array}$ & Revisão bibliográfica \\
\hline 4 & $\begin{array}{l}\text { Cornely, A. F. H. \& } \\
\text { Rocha, J. G. F. (2020). }\end{array}$ & $\begin{array}{l}\text { Avaliação e Manejo de } \\
\text { sintomas prolongados de } \\
\text { COVID-19. Universidade } \\
\text { Federal do Rio Grande do } \\
\text { Sul. Programa de Pós- } \\
\text { Graduação em } \\
\text { Epidemiologia. TelessaúdeRS } \\
\text { (TelessaúdeRS-UFRGS), } \\
\text { Porto Alegre: TelessaúdeRS- } \\
\text { UFRGS. }\end{array}$ & $\begin{array}{l}\text { Debater a avaliação e o manejo dos sintomas } \\
\text { prolongados de COVID-19 }\end{array}$ & Revisão bibliográfica \\
\hline 5 & $\begin{array}{l}\text { Daniel, C. R.; Baroni, } \\
\text { M. P.; Ruaro, J. A. \& } \\
\text { Fréz, A. R. (2020). }\end{array}$ & $\begin{array}{l}\text { Estamos olhando para os } \\
\text { indivíduos pós-COVID como } \\
\text { deveríamos? Rev. Pesqui. } \\
\text { Fisioter., Salvador, 10(4), } \\
\text { 588-90. }\end{array}$ & $\begin{array}{l}\text { Ampliar a visão do cuidado no âmbito da } \\
\text { avaliação multidimensional e intervenção para } \\
\text { os indivíduos } \\
\text { pós-COVID. }\end{array}$ & Revisão bibliográfica \\
\hline 6 & Mota, C. V. (2020). & $\begin{array}{l}\text { Coronavírus: a longa lista de } \\
\text { possíveis sequelas da Covid- } \\
\text { 19. BBC News Brasil, São } \\
\text { Paulo. }\end{array}$ & $\begin{array}{l}\text { Analisar os estudos divulgados a respeito das } \\
\text { possíveis sequelas decorrentes da COVID-19. }\end{array}$ & Revisão bibliográfica \\
\hline 7 & $\begin{array}{l}\text { Nogueira, T. L.; } \\
\text { Silva, S. D. A.; Silva, } \\
\text { L. H.; Leite, M. V. S.; } \\
\text { Rocha, J. F. A. \& } \\
\text { Andreza, R. S. } \\
\text { (2021). }\end{array}$ & $\begin{array}{l}\text { Pós covid-19: as sequelas } \\
\text { deixadas pelo Sars-Cov-2 e o } \\
\text { impacto na vida das pessoas } \\
\text { acometidas. Archives of } \\
\text { Health, Curitiba, 2(2), 457- } \\
71 .\end{array}$ & $\begin{array}{l}\text { Investigar as principais sequelas acarretadas } \\
\text { pela COVID-19 nos pacientes em reabilitação, } \\
\text { bem como a análise do impacto na qualidade } \\
\text { de vida e bem-estar desses indivíduos. }\end{array}$ & $\begin{array}{l}\text { Revisão bibliográfica } \\
\text { sistemática }\end{array}$ \\
\hline 8 & $\begin{array}{l}\text { Nunes, M. J. M.; } \\
\text { Silva, J. C. S.; } \\
\text { Oliveira, L. C.; } \\
\text { Marcos, G. V. T. M.; } \\
\text { Fernandes, A. C. L.; } \\
\text { Santos, W. L. S.; } \\
\text { Guzen, F. P.; }\end{array}$ & $\begin{array}{l}\text { Alterações Neurológicas na } \\
\text { Covid-19: uma Revisão } \\
\text { Sistemática. Revista de } \\
\text { Neurociências, Mossoró, 28, } \\
\text { 1-22. }\end{array}$ & $\begin{array}{l}\text { Revisar o material bibliográfico } \\
\text { existente que descrevem os impactos } \\
\text { neurológicos associados a COVID-19. }\end{array}$ & Revisão bibliográfica \\
\hline
\end{tabular}




\begin{tabular}{|c|c|c|c|c|}
\hline & $\begin{array}{l}\text { Cavalcanti, J. R. L. P. } \\
\text { \& Araújo, D. P. } \\
(2020) .\end{array}$ & & & \\
\hline 9 & $\begin{array}{l}\text { Oda, A. M. G. R. \& } \\
\text { Leite, S. (2020). }\end{array}$ & $\begin{array}{l}\text { A pandemia de COVID-19 no } \\
\text { Brasil: em busca de sentidos } \\
\text { em meio à tragédia } \\
\text { (Editorial). Rev. Latinoam. } \\
\text { Psicopat. Fund., São Paulo, } \\
\text { 23(3), 467-73. }\end{array}$ & $\begin{array}{l}\text { Discutir as questões relacionadas à pandemia } \\
\text { da COVID-19 frente à especificidades } \\
\text { nacionais. }\end{array}$ & Editorial \\
\hline 10 & $\begin{array}{l}\text { OPAS, Organização } \\
\text { Pan-Americana da } \\
\text { Saúde \& OMS, } \\
\text { Organização Mundial } \\
\text { da Saúde. (2020a). }\end{array}$ & $\begin{array}{l}\text { Transmissão do SARS-CoV-2: } \\
\text { implicações para as } \\
\text { precauções da prevenção e } \\
\text { infecção. }\end{array}$ & $\begin{array}{l}\text { Apresentar uma visão geral dos modos de } \\
\text { transmissão do SARS-CoV-2, o que se sabe } \\
\text { sobre quando as pessoas infectadas transmitem } \\
\text { o vírus e as implicações para as precauções de } \\
\text { prevenção e controle de infecções dentro e } \\
\text { fora das unidades de saúde. }\end{array}$ & $\begin{array}{l}\text { Consolidação de } \\
\text { revisões rápidas de } \\
\text { publicações em } \\
\text { periódicos com } \\
\text { revisão por pares e } \\
\text { artigos sem revisão } \\
\text { por pares em } \\
\text { servidores de preprint, } \\
\text { realizadas pela OMS e } \\
\text { parceiros }\end{array}$ \\
\hline 11 & $\begin{array}{l}\text { OPAS, Organização } \\
\text { Pan-Americana da } \\
\text { Saúde \& OMS, } \\
\text { Organização Mundial } \\
\text { da Saúde. (2020b). }\end{array}$ & $\begin{array}{l}\text { Alerta epidemiológico: } \\
\text { complicações e sequelas da } \\
\text { COVID-19. }\end{array}$ & $\begin{array}{l}\text { Apresentar um resumo das evidências } \\
\text { disponíveis sobre as complicações e sequelas } \\
\text { da COVID-19. }\end{array}$ & Revisão bibliográfica \\
\hline 12 & $\begin{array}{l}\text { Padilha, A.; Neto, C.; } \\
\text { Menezes, P. \& Sousa, } \\
\text { S. (2021). }\end{array}$ & Significado de Sequela. & Apresentar o conceito de sequela. & Revisão bibliográfica \\
\hline 13 & $\begin{array}{l}\text { Paz, L. E. S.; Bezerra, } \\
\text { B. J. S.; Pereira, T. } \\
\text { M. M. \& Silva, W. E. } \\
(2021) \text {. }\end{array}$ & $\begin{array}{l}\text { COVID-19: a importância da } \\
\text { fisioterapia na recuperação da } \\
\text { saúde do trabalhador. Rev } \\
\text { Bras Med Trab., 19(1), 94- } \\
106 .\end{array}$ & $\begin{array}{l}\text { Analisar as repercussões da COVID-19 sobre a } \\
\text { saúde do trabalhador, enfatizando a } \\
\text { importância da fisioterapia na recuperação dos } \\
\text { infectados. }\end{array}$ & Revisão integrativa \\
\hline 14 & Peres, A. C. (2020). & $\begin{array}{l}\text { Dias que nunca terminam: } \\
\text { sintomas persistentes } \\
\text { relacionados à Síndrome Pós- } \\
\text { Covid surpreendem pacientes } \\
\text { e pesquisadores. RADIS: } \\
\text { Comunicação e Saúde, } 218 \text {, } \\
26-31 \text {. }\end{array}$ & $\begin{array}{l}\text { Discutir os sintomas relacionados à síndrome } \\
\text { pós-COVID. }\end{array}$ & Revisão bibliográfica \\
\hline 15 & $\begin{array}{l}\text { Santana, A. V.; } \\
\text { Fontana, A. D. \& } \\
\text { Pitta, F. (2021). }\end{array}$ & $\begin{array}{l}\text { Reabilitação pulmonar pós- } \\
\text { COVID-19. J Bras Pneumol., } \\
\text { 47(e20210034), } 3 \text { p. }\end{array}$ & Analisar a reabilitação pulmonar pós-COVID. & Editorial \\
\hline 16 & $\begin{array}{l}\text { Silva, L. C. O.; Pina, } \\
\text { T. A. \& Ormond, L. } \\
\text { S. }(2021) \text {. }\end{array}$ & $\begin{array}{l}\text { Sequelas e reabilitação pós- } \\
\text { covid-19: revisão de } \\
\text { literatura. Revista das } \\
\text { Ciências da Saúde e Ciências } \\
\text { aplicadas do Oeste Baiano - } \\
\text { Higia, 6(1), 169-84 }\end{array}$ & $\begin{array}{l}\text { Analisar as sequelas e reabilitação pós- } \\
\text { COVID-19. }\end{array}$ & Revisão bibliográfica \\
\hline
\end{tabular}

Fonte: Autores (2021).

\section{Resultados e Discussão}

Entre as publicações selecionadas, foram encontrados artigos, pareceres e informes de entes municipais de disponibilização de Atenção à Saúde específica para pessoas com sequelas de COVID-19. Sobre esta última, faz-se essencial 
iniciar a fala exaltando a importância de lutar contra a normalização dos elevados números que permanecem se avolumando no decorrer da pandemia do novo coronavírus. Enquanto a situação de calamidade sanitária e de saúde estava em terras estrangeiras, era uma constante as demonstrações de lamento e de choque frente às perdas, verdadeira comiseração frente à enorme fila de carros levando corpos para serem cremados, como se as valas comuns abertas em solo brasileiro não tivesse a mesma dimensão... ou apenas se tornou normal. Enfrentar o SARS-CoV-2 vai além de enfrentar um vírus desconhecido, que resulta no desenvolvimento de uma doença igualmente desconhecida, mas que está nos levando ao confronto com nossas próprias limitações enquanto seres humanos, imperfeitos e limitados.

Nesse ínterim, Oda \& Leite (2020) reconhecem que situações extremas que resultam em destruição em massa, a exemplo de pestes e guerras, extrapolam o momento dos fatos, estendendo-se para além e afetando gerações no decorrer do tempo. Assim, surgem as sequelas físicas em pessoas que superaram a COVID-19, a exemplo de insuficiência cardíaca, fibrose pulmonar, problemas neurológicos e renais, por exemplo, além do comprometimento da saúde mental, como ansiedade, depressão, quadros de estresse pós traumático. Assim, soma-se essa nova realidade com as questões sociais, culturais, políticas, econômicas, emocionais e sanitárias que orbitam a atual pandemia.

Se analisarmos a pandemia através de números meramente, o horror é substituído por um entorpecimento dos sentidos, já que os números acabam não sendo capazes de expressar a dimensão das perdas que estamos presenciando. O confronto com o inominável, como podemos caracterizar esse momento que estamos enfrentando nos põe diante de desafios hercúleos, uma vez que o ser humano é um ser das palavras, dos afetos e dos sentidos. Caremos de interpretar, dar significado aos fatos, mesmo quando diante da perda, da dor, da desesperança e da tristeza. É justamente esse processo de enfrentamento que nos conecta ao que de mais humano há em cada um de nós, que nos habita e dá significado ao que vivenciamos. Assim, Oda \& Leite (2020, p. 470) são cirúrgicas quando apontam que “(...) pode-se dizer que os mortos pela pandemia são numerosos porém inumeráveis, (...), devem ser reconhecidos em suas experiências biográficas únicas”.

Ressalta-se assim, que não cabe uma análise restrita a números, mesmo em se tratando dessa estatística numericamente impressionante e devastadora que está sendo apresentada diariamente a nós relacionada à pandemia pelo SARS-CoV-2. Faz-se urgente romper com o real inominável atrelado à ela, uma vez que gera indiferença, e é essa indiferença com a morte que está atrelada ao descaso para com a vida. Urge um processo de revalorização da vida, seja existencial, seja preservacionista. Se te pergunto: o que nos ensina o vírus? Primeiramente é que, mesmo frente à devastação que ele está promovendo, a vida deve ser antes de qualquer outra coisa valorizada.

Assim, o que já ficou claro frente ao cenário que estamos enfrentando desde o $1^{\circ}$ trimestre de 2019 é que não se trata de uma gripezinha. Além da COVID-19 ter resultado em milhares de óbitos em todo o mundo, de acordo com o Painel Coronavírus, do Ministério da Saúde, somente no Brasil, de 27 de março de 2019 à 11 de julho de 2021, já foram 19.089.940 casos confirmados acumulados, com 533.488 óbitos registrados (Brasil, 2021).

Como resultado desse elevado poder de contaminação, as pessoas que superam a infecção se deparam com sequelas que comprometem suas atividades de vida diária (AVDs), inclusive as laborais, gerando um prejuízo imensurável. Do latim "sequela", sequela significa "ato de seguir", tendo ainda relação com sequência, continuação e indica o resultado, a consequência. Trazendo o conceito para a área médica, faz referência a qualquer lesão anatômica ou funcional que permanece após a evolução clínica de uma doença findar. Como consequência, representa dificuldade para o indivíduo afetado (Padilha, et al., 2021). Para facilitar o entendimento, utilizar-se-á neste estudo o entendimento de que uma sequela tem relação com uma condição que o indivíduo não possuía previamente decorrente de algum quadro clínico, anterior ao adoecimento, e que vai resultar em alterações na sua realidade e na sua qualidade de vida. 
Trazendo para o contexto da COVID-19 e tendo como referencial o significado apresentado, observa-se que o impacto é amplo e expressivo para as pessoas que se recuperam do vírus, especialmente porque tem relação com a presença de comorbidades anteriores ao adoecimento, não sendo uma condição determinante ter desenvolvido a forma grave da doença. $\mathrm{O}$ progresso também vai estar dependendo da gravidade e da extensão da lesão resultante da infecção viral.

O que já está servindo de direcionamento é a relação entre o vírus e a ECA2, que está sendo considerada um marcador das regiões mais vulneráveis do organismo humano, definido pela acumulação natural de tais receptores, uma vez que o SARS-CoV-2 as utiliza como meio de entrar nas células e se replicar. Assim, classifica-se a COVID-19 como uma doença sistêmica devido à sua capacidade de invasão em diferentes sistemas no organismo humano. Como consequência, caracteriza também os locais que são mais suscetíveis ao desenvolvimento de sequelas, sendo além dos pulmões (alvéolos pulmonares), o coração, o intestino e os rins, que apresentam lesões extensas e complexas em pessoas graves (Mota, 2020).

Além dessa relação da ECA2, Mota (2020, p. 01), faz uma reflexão sobre algumas possibilidades em relação aos danos decorrentes do SARS-CoV-2, observando que pode haver relação direta com o vírus ou com fatores indiretos à doença. As lesões identificadas nos vários órgãos afetados pós COVID-19 podem ser decorrentes da tempestade inflamatória gerada pelo sistema imune no combate ao vírus, ao inundar o organismo com citocinas ou podem ser consequências do próprio processo inflamatório gerado.

Com isso, observa-se que, no que se refere ao sistema respiratório, em sendo o pulmão o ponto inicial (também considerado marco zero) em que o vírus se instala, que é nele em que as sequelas são mais significativas e evidentes. Destaca-se a redução do volume e da capacidade pulmonar, principal consequência mesmo entre os adoentados que não atingiram estado crítico (Mota, 2020), dificuldades para a prática de exercícios físicos, ocasionando em perda funcional, cansaço, fadiga e dispneia, seja em repouso ou na execução de AVDs. No que tange ao sistema cardiovascular, observou-se lesão cardíaca aguda, inflamação vascular, arritmias e miocardites. Em se tratando das sequelas neurológicas, há impacto no trato olfatório causando hiposmia (diminuição do olfato) e disgeusia (distorção ou diminuição do paladar), apresentando-se de forma bem expressiva e persistente (Nogueira, et al., 2021; Campos, et al., 2020).

Nesse contexto, o SARS-CoV-2, responsável pela COVID-19, afeta o organismo humano desde o sistema respiratório ao diversos sistemas, como cardiovascular, renal, endócrino, nervoso, gastrointestinal e musculoesquelético, resultando em comprometimentos que podem ser temporários ou crônicos, podendo estar presentes mesmo anos após recuperado do adoecimento pela doença. Somado a essa realidade, o sedentarismo resultante do isolamento social impacta pessoas que apresentaram quadro assintomáticos e mesmo os não infectados, promovendo redução da capacidade funcional. Assim, pode-se concluir que a COVID-19 repercute a médio e longo prazo sobre a saúde humana, agindo de forma direta e indireta, gerando um inegável impacto socioeconômico, por comprometer a produtividade de trabalhadores ativos. Dentre esses trabalhadores, merece destaque aqueles da área da saúde, que acabam sendo infectados no exercício de suas funções pelo vírus (Paz, et al., 2021, p. 95).

Vale considerar ainda que em decorrência da ligação do SARS-CoV-2 com o receptor ECA2 que se dá o processo de invasão do patógeno no organismo humano, desencadeando as primeiras etapas da infecção viral na célula-alvo e aparecimento dos sinais clínicos da doença em decorrência da resposta imunológica do organismo à invasão. Mesmo o pulmão sendo o primeiro e principal local de instalação do vírus como já foi apresentado, ressalta-se que outros órgãos que possuem também este receptor podem ser acometidos, gerando, por consequência, manifestações clínicas específicas. Devido a essa questão, pode-se considerar a COVID-19 como sendo uma patologia de abordagem sistêmica, uma vez que para viabilizar o estabelecimento de um prognóstico fidedigno e otimista, faz-se necessário considerar que a disseminação viral ocorre entre órgãos vitais que possuam esta enzima em sua estrutura (Campos, et al., 2020). 
Como comprometimentos que as pessoas que apresentam as manifestações clínicas mais severas, em que há a necessidade de internação em UTI, acabam por demandar maior atenção assistencial integral, além de apoio médico 24 horas. Trata-se de um grupo de pessoas que envolvem altas taxas de mortalidade e, em decorrência dos longos períodos de hospitalização, apresentam desenvolvimento de patologias secundárias a COVID-19, em especial devido ao processo de intubação e/ou de ventilação mecânica (VM). Deve-se considerar que são intervenções que aumentam a vulnerabilidade da pessoa às infecções, apesar de serem utilizadas com o objetivo de restabelecer a capacidade respiratória que se encontra ineficaz. Ademais, estas pessoas estão suscetíveis desenvolverem a síndrome pós-cuidado intensivo, como resultado às complicações secundárias decorrentes dos procedimentos invasivos decorrentes da VM, do uso de sedativos, do bloqueio neuromuscular e imobilização por longos períodos, comprometendo o condicionamento físico e respiratório, perda de massa muscular, distúrbios cognitivos e neuropsiquiátricos (Nogueira, et al., 2021; Silva, Pina \& Ormond, 2021).

Mesmo sendo considerado o órgão-alvo no processo de adoecimento, além dos pulmões, outros órgãos como os rins, o fígado, o coração, o trato gastrointestinal, o SNC e hematopoiético sofrem com a hipóxia e a resposta inflamatória desencadeada pelo sistema imunológico. Como sequelas neurológicas mais simples é possível apontar as disfunções olfativas e gustativas persistentes, que são decorrentes do acometimento de células nervosas responsáveis por tais funções. Com a invasão do SARSCoV-2 no organismo humano pela via olfatória, este é direcionado ao SNC, passa pelo bulbo olfativo e outras regiões do cérebro (córtex, gânglios da base e o mesencéfalo), deixando sequelas por onde passa. Também foram registradas outras sequelas, como cefaleia, tontura e sensação de raciocínio lento. Já o déficit neurológico é mais comumente relatado como manifestações mais graves, além do registro com maior raridade de acidente vascular isquêmico (AVI), convulsões, encefalite e neuropatias cranianas (Paz, et al., 2021; Campos, et al., 2020; Nunes, et al., 2020; Cornely \& Rocha, 2020).

Dependendo da extensão e da gravidade da infecção viral, as alterações do sistema respiratório de longo prazo estão relacionadas a redução da capacidade de difusão do monóxido de carbono (comprometendo a oxigenação tecidual), a limitada capacidade de praticar exercícios físicos e, nos quadros mais agudos da infecção, desenvolvimento de fibrose pulmonar. Pesquisadores supõem que tais danos relacionados ao sistema respiratório à liberação de citocinas provocadas pelo vírus, à toxicidade pulmonar, à lesão pulmonar aguda subjacente à VM de forma recorrente e a alta pressão nas vias aéreas (Nogueira, et al., 2021).

As sequelas no sistema cardiovascular estão mais comumente relacionadas à fibrose intersticial miocárdica, à hipóxia, à inflamação sistêmica (miocardite) e à lesão miocárdica. Além disso, estão relacionadas aos acometimentos do sistema respiratório. Tal relação se deve tanto às comorbidades presentes que aumentam a vulnerabilidade da ocorrência de danos mais extensos, quando da presença da ECA2 nas estruturas cardíacas (cardiomiócitos e pericitos), fator esse que contribui no processo de entrada do patógeno nas células e na sua replicação (OPAS \& OMS, 2020b).

Uma das principais queixas após o enfrentamento da infecção pelo SARS-CoV-2 é a limitação musculoesquelética que tem relação à perda de força muscular e sarcopenia (resposta inflamatória ao vírus, nutrição insuficiente e imobilidade associada à hospitalização). Acometendo pelo menos $25 \%$ das pessoas que passaram pela COVID-19, tais sequelas impactam direta e intensamente as AVDs, comprometendo a qualidade de vida dessas pessoas, de ordem físico-funcional (Paz, et al., 2021; Campos, et al., 2020).

No que se refere aos distúrbios de ordem psicológicas, quadros depressivos, ansiedade e estresse pós traumático pode ocorrer especialmente pela relação com as medidas de isolamento social, pelo sofrimento decorrente da fragilização no enfrentamento do luto decorrente da perda de entes familiares, pelo medo frente ao risco potencial de vir a morrer e pelo cenário de instabilidade econômica e social no qual todos os brasileiros estão inseridos. Dessa forma, o risco pode ultrapassar 60\% entre as pessoas hospitalizadas ou já em processo de reabilitação (Campos, et al., 2020). 
Um fato que merece atenção, após discorrer sobre as principais sequelas decorrentes do adoecimento pela COVID-19 é que, assim como em epidemias resultantes de outros coronavírus (SARS e MERS), é a ocorrência de sequelas que perduram por meses e até anos, dependendo do caso. Também se há de considerar que nem sempre essa nova condição é temporária, apresentando-se como crônica, como é o caso da fibrose pulmonar (um dos resultados da entubação nas pessoas assistidas em estado crítico), decorrente de lesão pulmonar que é provocada pela VM inadequada (Mota, 2020).

O que é inquestionável frente à problemática que está só começando relacionada ao pós adoecimento por COVID-19 é que muitas estão sendo as medidas que se tem buscado implementar a fim de garantir segurança à população em geral. Incontáveis estratégias de saúde pública visando o controle da taxa de disseminação por parte dos indivíduos assintomáticos, que mesmo sem apresentar sinais ou sintomas da doença, estão com o vírus no seu organismo e o transmite, complicando a sua identificação e o isolamento do indivíduo (OPAS \& OMS, 2020a).

A reabilitação a fim de promover a recuperação das pessoas que passaram pela infecção, seja de déficits físicos, funcionais ou mesmo mentais deve ser acompanhada por equipe multidisciplinar. O foco deve ser a promoção da saúde, objetivando a maximização da independência e da capacidade de cada indivíduo, sempre considerando as necessidades subjetivas que venha a apresentar (Silva, Pina \& Ormond, 2021). Vale considerar que a presença de sintomas prolongados de fadiga e dispneia é indicativo de necessidade de reabilitação cardiopulmonar, focando a redução das limitações apresentadas nos sistemas envolvidos. Para casos de anosmia persistente o de mais eficiente identificado é o treinamento olfatório, que busca promover a regeneração dos neurônios que foram afetados pela infecção viral, uma vez que intervenções farmacológicas não foram ainda desenvolvidas (Daniel, et al.; 2020).

Em relação às sequelas neuropsiquiátricas carecem de um acompanhamento singular, holístico e estratégico. Trazer a família nesse processo de reabilitação influencia na adesão ao tratamento que somada à equipe multiprofissional será promovida a plena recuperação dessa pessoa assistida. $\mathrm{O}$ atendimento remoto se tornou uma realidade em tempos de pandemia, em que a prioridade é não deixar o indivíduo desassistido em suas demandas e adotando parâmetros da redução de danos dada sua forma prática no que tange a lugar e tempo, sem comprometer a necessidade do devido distanciamento social que o momento ainda requer (Santana, Fontana \& Pitta, 2021).

Barreto e colaboradores (2020) reconhecem a multiplicidade de fatores que se tem sido necessário enfrentar na escolha de estratégias governamentais de enfrentamento ao SARS-CoV-2, a fim de buscar soluções para os variados cenários sanitários e socioeconômicos. Tal realidade se deve à sua complexidade, às características particulares do vírus (rápida disseminação e elevado potencial de risco de vida dos infectados), além da falta de conhecimentos científicos acumulados sobre o vírus e a doença.

O que já se sabe afirmar é que as pessoas que se recuperaram da COVID-19 passaram a apresentar anosmia, ageusia, mialgia e artralgia, fadiga, taquicardia, hipertensão ou hipotensão sem causa determinada, dispneia persistente evidenciado em desconforto respiratório em repouso ou aos mínimos esforços, inclusive com aperto no peito. O que fica como incógnita é a causa desses comprometimentos, o porquê dessas complicações extrapulmonares, sua duração e as consequências a médio e a longo prazo que podem desencadear (Peres, 2020).

No que se refere à prevenção, as vacinas, ainda que escassas para que possam promover um impacto negativo dos índices de contaminação e de óbito, representam verdadeiras tábuas da salvação, mas não garantem a não infecção pelo vírus. Assim, deve-se manter as medidas de cuidado individual, especialmente a lavagem das mãos, o uso de máscaras, a etiqueta respiratória, a limpeza de superfícies e de isolamento social, sendo respeitada a distância física, aglomerações e exposições desnecessárias. São medidas que foram consensuadas por entidades nacionais e internacionais e que focam na proteção de toda a população (Allegrante, et al., 2020). 
Ademais, quando se fala em morbidade no contexto da COVID-19, vale considerar que o Brasil enfrentará dificuldades relacionadas ao componente de morbidade (YLD), impactando o panorama clínico-epidemiológico no que diz respeito às complicações agudas e crônicas resultantes da COVID-19. Faz-se necessário tempo para poder ser realizada uma análise fidedigna e segura, dado o exíguo período de investigações dos casos recuperados no pós COVID-19. O que já se identifica são os desafios que serão enfrentados no mapeamento dessas complicações e no estabelecimento de parâmetros clínicoepidemiológico do agravo (Campos, et al., 2020, p. 03).

Assim, descortina-se que a implementação e manutenção das medidas preventivas e de monitoramento no Brasil configuram desafio extremamente difícil. Mesmo com o intenso apoio da comunidade científica nesse enfrentamento aos gestores públicos, é no Sistema Único de Saúde (SUS) que se destaca a essencial resposta a nível assistencial e nas Universidades públicas a frente voltada ao desenvolvimento de soluções mediante a pesquisa (Oda \& Leite, 2020).

\section{Considerações Finais}

Diante de todo o exposto sobre as sequelas, algo surpreendente é que nem sempre é a pessoa assistida em estado grave que apresenta comprometimentos significativos no pós adoecimento. A grande maioria de relatos das pessoas assistidas envolvem aquelas que apresentaram a forma branda ou moderada da COVID-19, permanecendo após a recuperação da infecção com algum tipo persistente de sequela, conforme observa Peres (2020). A síndrome pós COVID (ou long covid, do inglês "COVID longa") representa um quadro clínico que é resultante da repercussão do agravo no organismo e que é composto por um conjunto de sintomas inespecíficos. Em sendo um algo recente, ainda não se sabe muito a seu respeito, mas o que fica claro é que não acomete apenas pessoas que desenvolveram a forma grave da COVID-19 e que chegaram a ser internadas em UTI por longo período.

A crise política que é enfrentada nos vários níveis de poder, seja pelas decisões baseadas no negacionismo à doença e à sua letalidade, seja na falta de ações orquestradas no combate à pandemia exige medidas sistemática e voltadas à proteção à vida e ao reconhecimento da dor dos milhares e milhares de enlutados em todo o país

Nesse cenário, como resposta direcionada ao reconhecimento da problemática de saúde pública que a COVID-19 vai gerar em pouco tempo futuro em relação aos milhares de brasileiros que terão no pós infecção a batalha por recuperar sua independência e dignidade fragilizadas pelo processo de adoecimento, os municípios precisam encontrar caminhos para dar resposta às demandas que já começaram a surgir. O que fica claro é a necessidade de que sejam respeitados critérios essenciais como a humanização do cuidado, o acesso a todos que dele necessite e o atendimento ao indivíduo de forma holística.

Ademais, é fator inquestionável a necessidade que sejam intensificados esforços que visem a promoção da acumulação de conhecimentos a respeito do SARS-CoV-2, de como se desenvolve a COVID-19 no organismo humano e quais as consequências que o indivíduo e os profissionais da saúde terão que enfrentar. Assim, explicita-se a intenção de contribuir nesse processo através da publicação dos achados relacionados à dissertação já em fase de conclusão, do qual esse trabalho representa apenas um recorte, bem como de outros olhares a respeito da temática.

\section{Referências}

Allegrante, J. P.; Auld, M. E. \& Natarajan, S. (2020). Preventing COVID-19 and its Sequela: “There is no Magic Bullet... It's Just Behaviors". American journal of preventive medicine, 59(2), 288-92.

Barreto, M. L.; Barros, A. J. D.; Carvalho, M, S.; Codeço, C. T.; Hallal, P. R. C.; Medronho, R. A.; Struchiner, C. J.; Victora, C. G. \& Werneck, G. L. (2020). O que é urgente e necessário para subsidiar as políticas de enfrentamento da pandemia de COVID-19 no Brasil? Revista Brasileira de Epidemiologia, 23(e200032).

Brasil, República Federativa do. (2021). Ministério da Saúde. Painel Coronavírus. 2021. Recuperado de https://covid.saude.gov.br/. 
Brasil, República Federativa do. (2020). Ministério da Saúde. Secretaria de Atenção Especializada à Saúde. Departamento de Atenção Hospitalar, Domiciliar e de Urgência. Protocolo de manejo clínico da Covid-19 na Atenção Especializada. 1. ed. rev. Brasília: Ministério da Saúde. 48 p.

Campos, M. R.; Schramm, J. M. A.; Emmerick, I. C. M.; Rodrigues, J. M.; Avelar, F. G. \& Pimentel, T. G. (2020). Carga de doença da COVID-19 e de suas complicações agudas e crônicas: reflexões sobre a mensuração (DALY) e perspectivas no Sistema Único de Saúde. Cadernos de Saúde Pública, 36(11).

Cornely, A. F. H. \& Rocha, J. G. F. (2020). Avaliação e Manejo de sintomas prolongados de COVID-19. Universidade Federal do Rio Grande do Sul. Programa de Pós-Graduação em Epidemiologia. TelessaúdeRS (TelessaúdeRS-UFRGS), Porto Alegre: TelessaúdeRS-UFRGS.

Daniel, C. R.; Baroni, M. P.; Ruaro, J. A. \& Fréz, A. R. (2020). Estamos olhando para os indivíduos pós-COVID como deveríamos? Rev. Pesqui. Fisioter., Salvador, 10(4), 588-90.

Ferreira, N. S. A (2002). As pesquisas denominadas" estado da arte". Educação \& Sociedade, 23(79), 257-272.

Mota, C. V. (2020). Coronavírus: a longa lista de possíveis sequelas da Covid-19. BBC News Brasil, São Paulo. Recuperado de https://www.bbc.com/portuguese/geral-53654692.

Nogueira, T. L.; Silva, S. D. A.; Silva, L. H.; Leite, M. V. S.; Rocha, J. F. A. \& Andreza, R. S. (2021). Pós covid-19: as sequelas deixadas pelo Sars-Cov-2 e o impacto na vida das pessoas acometidas. Archives of Health, Curitiba, 2(2), 457-71.

Nunes, M. J. M.; Silva, J. C. S.; Oliveira, L. C.; Marcos, G. V. T. M.; Fernandes, A. C. L.; Santos, W. L. S.; Guzen, F. P.; Cavalcanti, J. R. L. P. \& Araújo, D. P. (2020). Alterações Neurológicas na Covid-19: uma Revisão Sistemática. Revista de Neurociências, Mossoró, 28, 1-22.

Oda, A. M. G. R. \& Leite, S. (2020). A pandemia de COVID-19 no Brasil: em busca de sentidos em meio à tragédia (Editorial). Rev. Latinoam. Psicopat. Fund., São Paulo, 23(3), 467-73.

OPAS, Organização Pan-Americana da Saúde \& OMS, Organização Mundial da Saúde. (2020a). Transmissão do SARS-CoV-2: implicações para as precauções da prevenção e infecção. https://iris.paho.org/bitstream/handle/10665.2/52472/OPASWBRA COVID-1920089_por.pdf?sequence=1\&isAllowed=y.

OPAS, Organização Pan-Americana da Saúde \& OMS, Organização Mundial da Saúde. (2020b). Alerta epidemiológico: complicações e sequelas da COVID$19 . \quad$ ttps://www.paho.org/bra/dmdocuments/covid-19-materiais-decomunicacao1/Alerta\%20epidemiologico\%20-\%20Complicacoes\%20e\%20sequelas\%20da\%20COVID-19.pdf.

Padilha, A.; Neto, C.; Menezes, P. \& Sousa, S. (2021). Significado de Sequela. Recuperado de https://www.significados.com.br/sequela/.

Paz, L. E. S.; Bezerra, B. J. S.; Pereira, T. M. M. \& Silva, W. E. (2021). COVID-19: a importância da fisioterapia na recuperação da saúde do trabalhador. Rev Bras Med Trab., 19(1), 94-106.

Peres, A. C. (2020). Dias que nunca terminam: sintomas persistentes relacionados à Síndrome Pós-Covid surpreendem pacientes e pesquisadores. RADIS: Comunicação e Saúde, 218, 26-31.

Santana, A. V.; Fontana, A. D. \& Pitta, F. (2021). Reabilitação pulmonar pós-COVID-19. J Bras Pneumol., 47(e20210034), 3 p.

Silva, L. C. O.; Pina, T. A. \& Ormond, L. S. (2021). Sequelas e reabilitação pós-covid-19: revisão de literatura. Revista das Ciências da Saúde e Ciências aplicadas do Oeste Baiano - Higia, 6(1), 169-84. 